\title{
Environmental Barrier Coating (EBC) Durability Modeling; An Overview and Preliminary Analysis
}

\begin{tabular}{|r|l|}
\hline Journal: & MS\&T 2011 Ceramic Transactions \\
\hline Manuscript ID: & 50144.R1 \\
\hline Symposium: & Ceramic Matrix Composites \\
\hline $\begin{array}{r}\text { Date Submitted by the } \\
\text { Author: }\end{array}$ & n/a \\
\hline Complete List of Authors: & Aziz, Ali; NASA Glenn Research Center/CSU, \\
\hline \multicolumn{2}{|c}{} \\
\hline
\end{tabular}

\section{SCHOLARONE \\ Manuscripts}




\title{
Environmental Barrier Coating (EBC) Durability Modeling; An Overview and Preliminary Analysis
}

\author{
A. Abdul-Aziz, R. T. Bhatt, J. E. Grady and D. Zhu \\ NASA Glenn Research Center \\ Cleveland, Ohio 44135
}

Keywords: EBC, CMC, Fracture Mechanics, NDE, Spallation, Finite Element, Durability

\begin{abstract}
A study outlining a fracture mechanics based model that is being developed to investigate crack growth and spallation of environmental barrier coating (EBC) under thermal cycling conditions is presented. A description of the current plan and a model to estimate thermal residual stresses in the coating and preliminary fracture mechanics concepts for studying crack growth in the coating are also discussed. A road map for modeling life and durability of the EBC and the results of FEA model(s) developed for predicting thermal residual stresses and the cracking behavior of the coating are generated and described. Further initial assessment and preliminary results showed that developing a comprehensive EBC life prediction model incorporating EBC cracking, degradation and spalling mechanism under stress and temperature gradients typically seen in turbine components is difficult. This is basically due to mismatch in thermal expansion difference between sub-layers of EBC as well as between EBC and substrate, diffusion of moisture and oxygen though the coating, and densification of the coating during operating conditions as well as due to foreign object damage, the EBC can also crack and spall from the substrate causing oxidation and recession and reducing the design life of the EBC coated substrate.
\end{abstract}

\section{Introduction}

The need for increasing the cycle efficiency and reducing NOx emission and noise in future gas turbine engines has promoted development of fiber reinforced ceramic matrix composites (FRCMC), specifically $\mathrm{SiC}$ fiber reinforced $\mathrm{SiC}$ matrix composites ( $\mathrm{SiC} / \mathrm{SiC})$ for the structural hot section components [1]. These materials not only are lighter, but also can operate at about $200{ }^{\circ} \mathrm{C}$ hotter than current metallic materials. In dry air, these materials form a protective silica layer on the surface and thus are stable at temperatures up to $1300^{\circ} \mathrm{C}$ for long-term applications. However in combustion environments containing moisture, these materials show surface recession due to decomposition of protective silica and active oxidation of the substrate, and the rate of recession also increases with increasing gas velocity [2-6]. To reduce moisture diffusion and surface recession issues, a variety of environmental barrier coatings (EBC) have been developed. The upper-use temperatures of these EBCs vary between 1200 to $1650{ }^{\circ} \mathrm{C}$ depending on the composition [7-11].These coatings also recess with time at temperatures $>1400^{\circ} \mathrm{C}$, but rate of recession is an order of magnitude or two lower than that of the uncoated substrate at the same temperature. For successful use of CMCs in turbine components, these coatings need to be prime reliant which means that life of the 
coated CMCs depends on coating and not the uncoated substrate life. In other words if the coating spalls off, the CMC substrate life is drastically reduced .This design concept is directly in contrast with the design concept of thermal barrier coated metal parts in current engines where design life of TBC coated metal is based on the life of uncoated metal under engine operating conditions. Currently, failure mechanisms of EBC under steady state and transient conditions are not fully understood or models to predict life of EBC do not exist. Therefore, determining the factors influencing EBC stability, mechanisms of EBC degradation and failure modes, and developing models to predict durability and life of an EBC alone and $\mathrm{CMC}$ after the EBC failure are critical for introducing $\mathrm{EBC}$ coated CMC components in engines.

The overall goals of this study are several: (1) To generate thermo-mechanical and crack growth properties for as-coated model EBC system; (2) To model thermal residual stress in the as-processed EBC; (3) To model failure behavior of EBC under 3point flexural tests; (4) To develop model to predict conditions under which cracks in the coating are deflected and penetrated through-the-thickness; (5) To monitor crack initiation and crack growth and spallation of the coating with thermal cyclic conditions with and without imposed mechanical stress via NDE and electro-optical methods; and (6) To develop and validate fracture mechanic based FEA models to predict life of the coating. However, in this study, a road map for modeling life and durability of the EBC and the results of FEA model(s) developed for predicting thermal residual stresses in the coating and the cracking behavior of the coating are discussed.

\section{EBC processing methods}

Generally an EBC system is made up out of two or more layers of coating, in which each layer serves a specific purpose. The composition, total thickness and the processing methods for EBC can vary depending on the component type and intended life requirements of the coating. Currently EBC system is deposited by four methods: (a) Air plasma spray (APS); (b) Electron beam assisted physical vapor deposition (EB-PVD); (c) sputtering; and (d) slurry deposition. The microstructure, elastic and fracture properties of the coating deposited by above methods can vary significantly. A typical microstructure of an APS coated $\mathrm{EBC}$ on $\mathrm{SiC} / \mathrm{SiC}$ substrate shown in figure 1 indicates crack pattern on the top coat, and pore size and micro-crack distribution in sub-layers of the EBC system.

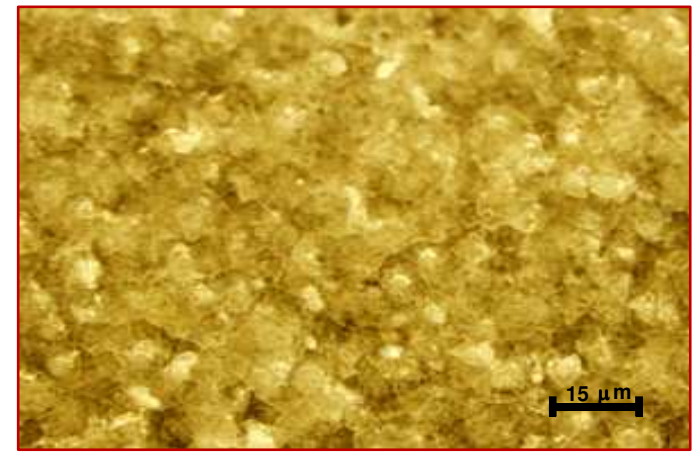

(a)

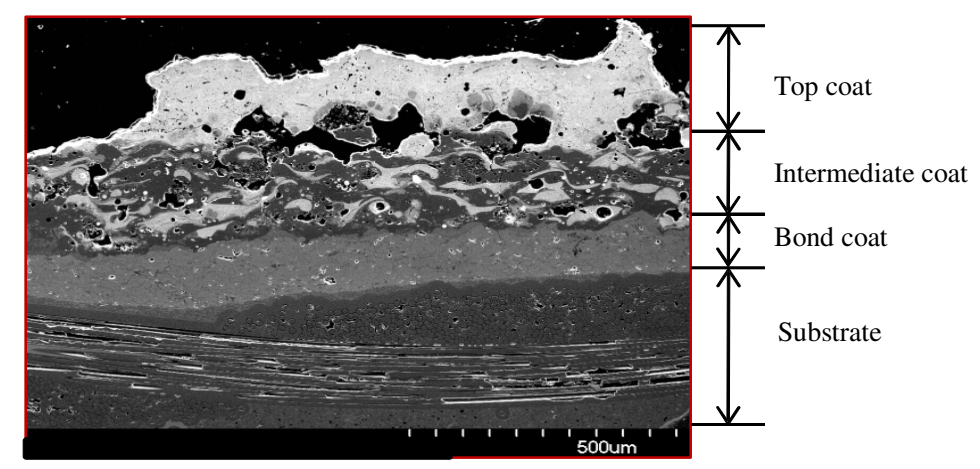

(b)

Figure 2.Typical microstructure of plasma sprayed $\mathrm{EBC}$ on $\mathrm{SiC} / \mathrm{SiC}$ composites: a)Top view (optical micrograph), and (b) cross-sectional view with SEM. 
Since the thermal and mechanical properties of the coatings and the substrate are different and since the sub-layers are applied at different processing temperatures, thermal residual stresses are generated in the coating. Under engine operating conditions, oxygen and moisture permeates through the coating, and the coating thickness changes due to densification. Therefore microstructure, phase composition, thermal residual stresses, thermal and mechanical properties of the coating continuously changes with exposure time. Depending on the magnitude and nature of residual stresses, the coating may crack after deposition or after exposing the coated substrate to turbine operating conditions.

\section{EBC failure modes}

EBC can spall-off from the substrate during thermo-mechanical cycling or due to foreign object damage and failure modes can vary depending on the exposure conditions. Under thermal cycling condition without stress two failure modes have been observed [12-13]:

(1) Formation of through-the-thickness cracks spanning from the top coat to bond/intermediate coat interface or to bond coat/substrate interface followed by formation and growth horizontal crack along the respective interfaces, linkage of the cracks and eventual spallation of the coating. Also, coating interface reactions and internal pore formation further accelerate coating spallation. Schematics of the generalized failure mechanisms are shown in figure 2.

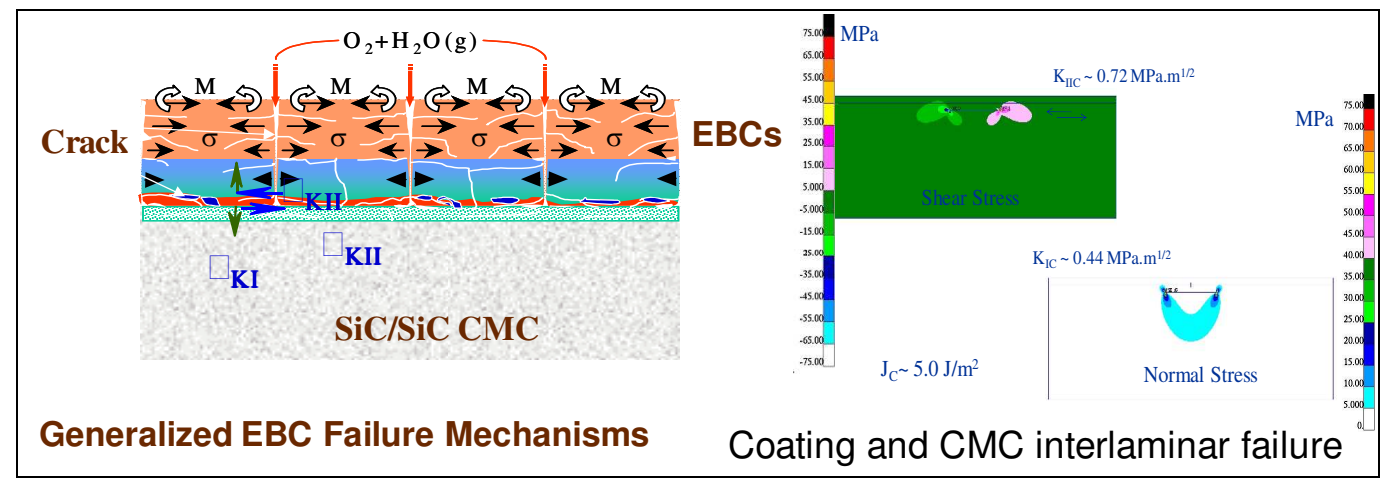

Figure 2. Failure mechanisms in EBC

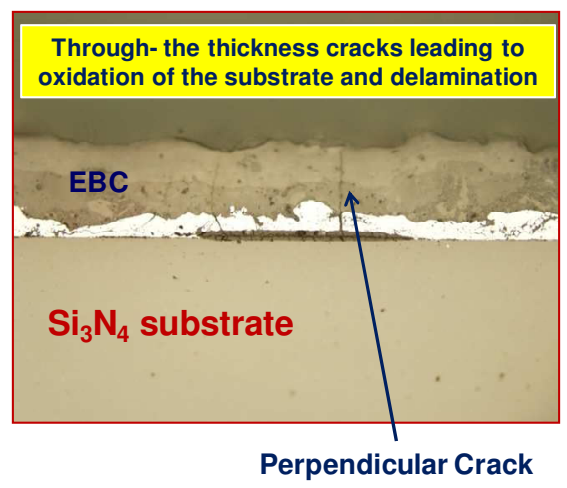


Figure 3. Optical photographs of the cross-sections of coated silicon nitride thermally cycled at $1382^{\circ} \mathrm{C}$ for $100 \mathrm{hrs}$ in a moisture containing environment

Stress contour from a finite element based analysis shows the inter-laminar failure of the coating and CMC stress distribution due to thermal and mechanical loading, figure 2. Observation of the above mechanism in an EBC coated $\mathrm{Si}_{3} \mathrm{~N}_{4}$ subjected to thermal cycling test in a moisture environment at $1382^{\circ} \mathrm{C}$ for $100 \mathrm{hrs}$ is shown figure 3.

(2) Diffusion of oxygen and moisture through the coating to the substrate/bond coat interface followed by oxidation of substrate, formation of pore, linkage of the pore and eventual spallation of the coating. This mechanism is observed when the thermal expansion of the substrate closely matched with that of the coating. An example of this mechanism is shown in figure 4 which shows pore formation at the substrate/coating interface leading to coating delamination.

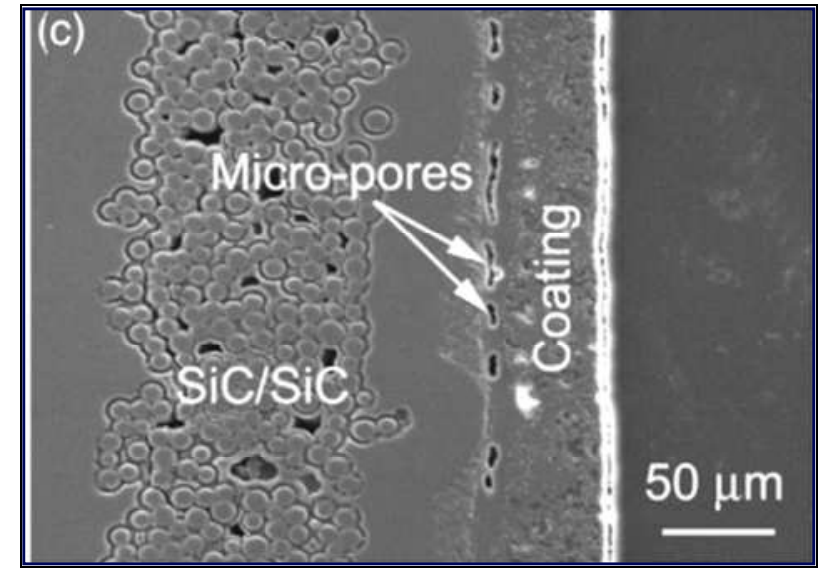

Figure 4. SEM photograph of a cross-section of mullite $/ \mathrm{Gd}_{2} \mathrm{SiO}_{5}$ coated MI-SiC/SiC composite coupons after 200 thermal cycles at $1350^{\circ} \mathrm{C}$ in a moisture environment.

\section{EBC Model}

As indicated above, the EBC coated CMC substrate when exposed to flowing combustion environment containing moisture several things happens to the coating simultaneously: EBC recesses, moisture and oxygen from the flowing environment diffuse through the coating, atomic diffusion occurs between the sub-layers of the coating, coating sub-layers densifies and thermal residual stresses within the coating change. As a result, the microstructure and physical and mechanical properties of the coating continuously evolves with exposure time at a fixed temperature or during temperature/stress cycles. Due to thermal expansion mismatch between sub-layers of the $\mathrm{EBC}$ and between the EBC and the substrate as well as continuously evolving microstructure of the EBC, spallation of the EBC occurs by two different mechanisms as stated above. Therefore development of a life prediction model requires the constitutive properties of the as-deposited EBC layers and variation of these properties as the microstructure of the coating evolves during exposure with and without stress, failure modes of the EBC, crack initiation, propagation, and spallation times, recession rate of 
the coating, magnitude of the thermal residual stress in the as-processed EBC and during exposure, diffusion rate oxygen and moisture within the coating as shown in bubble diagram of figure 5. For predicting life of the EBC coated CMC turbine components under engine operating conditions, a comprehensive model incorporating all the modeling elements shown in the bubble diagram is needed.

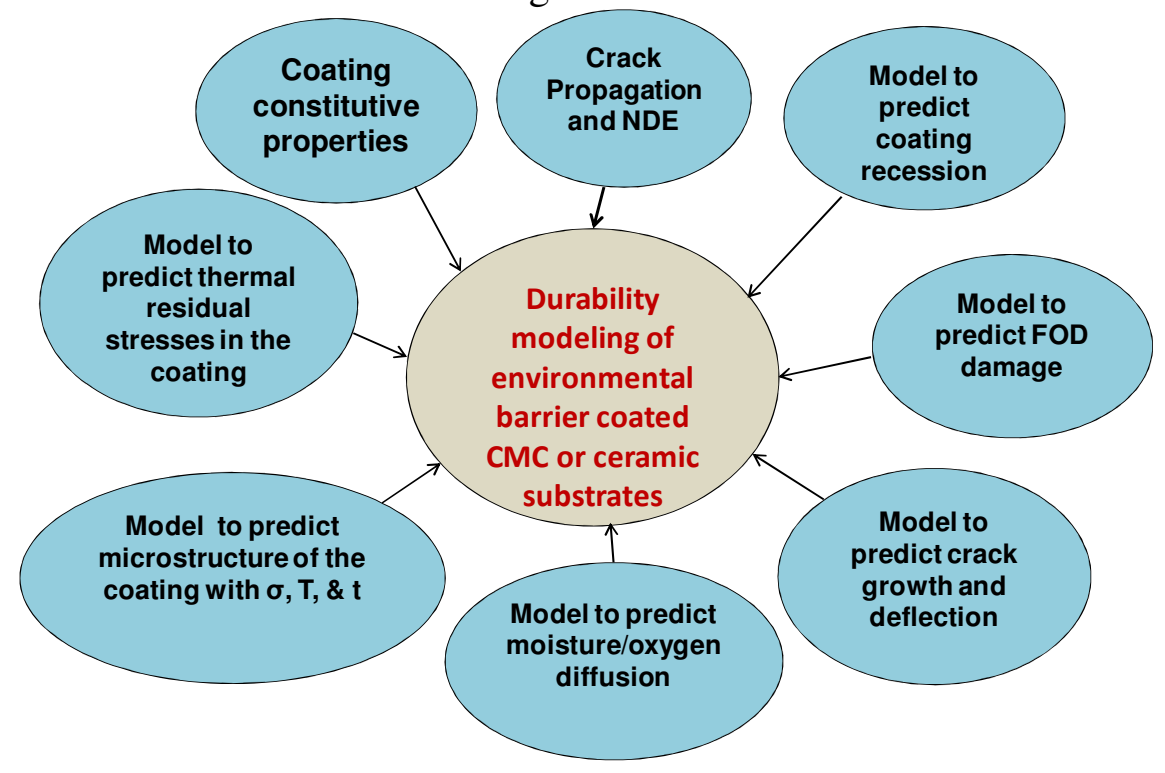

Figure 5. Durability modeling of environmental barrier coating.

Because of the complexity of modeling life of EBC, a simplified fracture mechanics model will be developed initially without incorporating diffusional phenomena, coating recession and sintering effects. This model when fully developed should predict thermal residual stresses, crack initiation, propagation, and spallation (delamination) behavior of EBC.

A model to predict thermal residual stress in the coating has been developed and results have been documented and discussed in reference [14]. Currently, the crack propagation behavior in an EBC coated $\mathrm{CMC}$ with single edge notch subjected to external stress and thermal cycling is being studied by computed tomography (CT) to further perform the combined NDE/FEA modeling.

\section{Analytical Modeling}

Two options are being considered to model the EBC durability; (1) physics based approach that focus on the layout described in figure 5 and shall include supportive experimental initiatives to complement and verify the analytical data. It is expected to record the baseline microstructure and crystallinity of EBC and thickness variation of individual EBC layers and expose the EBC coated $\mathrm{CMC}$ in air and moisture environments at temperatures up to $1400^{\circ} \mathrm{C}$ for up to 500 hours and thermal cycle it without stress in a moisture environment. Crack propagation phenomenon will be addressed via inducing an artificial crack or an indentation in the EBC. Crack propagation is to be conducted under stress and thermal cycling conditions. 
The ultimate goal is to establish a stress-strain failure baseline using experimentally driven materials data and examine the impingement of the crack behavior at the interface of the EBC/CMC stack to enable deriving a correlation leading to establishing when the crack is arrested or advanced by either penetrating the interface or deflecting into the interface. The analytical model will attempt to account for environmental and operational conditions such as oxidation, interface roughness, creep, sintering, failure assessments under thermal cycling, and failure assessments under thermo-mechanical fatigue cycling, impact modeling of foreign object damage (FOD). Modeling is to include both isothermal and thermal gradient loading conditions. Life prediction will follow and it will be based upon acquiring optimum data and results. Such data will be confined to obtaining information relevant to the constitutive properties of the substrate and the coating, influence of time, temperature, stress and moisture on the coating, coating recession information, diffusion rates of species from the substrate to the coating and within the coating, measured values of the residual stresses in the coating, coating deposition conditions and coating failure criteria and damage information. Finite element will be the base numerical method used for these studies along with supportive commercial software such as MSC/MARC [14], MSC/Patran [15] and Abaqus [16].

(2) NDE-FEA approach is to be performed along the proposed physics based methodology to correlate imaging data obtained from sources such as computer tomography (CT), X-rays etc... and apply reverse engineering principals by using the finite element computational method to model tested specimen under thermal and mechanical loading conditions. Segmented images can be exported as stereographic (STL) or Initial Graphics Exchange Specification (IGES) files for computer aided design (CAD) geometry and finite element analysis. This methodology will allow using a broad range of image visualization, processing and segmentation tools available to incorporate and utilize state of the art facilities at NASA GRC to execute NDE related tests and assessments to evaluate CMC/EBC coated specimens and permit a combined NDEcomputational verification.

Unique meshing capabilities for creating 3D image based models of supreme accuracy and sophistication is very feasible [17]. The modeling plan is to consist of; (1) conducting computer tomography scans using baseline-unloaded specimen; (2) test load the specimen under three point or four bend conditions at various loads and re-scan the loaded specimen and assess damage and structural changes; (3) thermal cycle tested specimen at three time intervals of 10,50 and 100 hours and re-scan at different time intervals; (4) perform image processing, segmentation and 3-D volume rendering of tested specimen. Crack measurements and other micro-deformities if any for each test case will be also performed for crack dimensioning purpose ; (5) The final segment of this modeling approach will include analyzing the as tested specimen geometry including all structural deformities and defects for each test case using the NDE-CT scan information. A follow up diagram will incorporate replicating the outlined plan using a specimen with an artificially induced crack on the top surface (at the top coating) not to exceed $20 \mathrm{~mm}$. 
However, it should be noted that due a certain design limitations the CT scanning will only embrace a specified region of the test specimen with a designated area size and location. This is due to the fact that the highest and desirable CT scan resolution of $\sim 5$ $\mu \mathrm{m}$ can only be achieved if a small area is targeted. As a result, this will hinder the ability to analyze the entire specimen and will only enable modeling the area of interest. Nevertheless, suitable assumptions and application of appropriate boundary conditions should compensate for these limitations.

\section{Preliminary Results}

A general finite element model was developed for estimating the residual stresses in coated substrates based on the known processing conditions of the coating, the specimen geometry of the coated substrate, and the thermo-mechanical properties of the coated layers and the substrate. The analytical modeling assumed that the substrate is maintained at $1200^{\circ} \mathrm{C}$ during deposition of the plasma spray coating and then cooled to room temperature. The analysis performed did not include effects of conditions such as creep and fracture propagation due to simplicity and unavailability of other supportive data. However, plans to incorporate these effects and other relevant ones are planned to be addressed in the proposed analytical modeling presented in this article. Figure 7 shows the predicted residual stresses for the EBC system shown in Table I. The material property data for the coating constituents and the substrate and details of the FEA model used for predicting thermal residual stresses are from reference [18]. Part (a) of figure 7 represents the predicted in plane and through-the-thickness thermal residual stresses in the coating as a function of the normalized distance.

Table I. Analytical cases and coating systems considered.

\begin{tabular}{|c|c|}
\hline System & $\begin{array}{c}\text { Coating } \\
\text { Thickness }\end{array}$ \\
\hline $\begin{array}{c}\text { Top Coat- Barium Strontium } \\
\text { aluminum silicate (BSAS) }\end{array}$ & $75 \mu \mathrm{m}$ \\
\hline $\begin{array}{c}\text { Intermediate coat } \\
\text { Mullite + (BSAS) }\end{array}$ & $75 \mu \mathrm{m}$ \\
\hline Bond coat-silicon & $75 \mu \mathrm{m}$ \\
\hline SiC-SiC substrate & $3 \mathrm{~mm}$ \\
\hline
\end{tabular}

Included in the results for comparison is the fracture strength range of standalone EBC layers (the hatched band). It is clear that the in-plane or X-Y stresses are much higher than the through-the-thickness stresses; in fact the through-thickness stresses are negligible. The intermediate coat experienced higher stress than the bond or the topcoats mainly due to a greater difference in the coefficient of thermal expansion (CTE) mismatch between the intermediate coat and the substrate. Figure 7 (b) shows the predicted in plane and through-the-thickness thermal residual stresses in the substrate. In general, the in-plane stresses at the substrate/coating interface is mostly compressive and small, but with increasing distance away from the interface the stresses decreased gradually and then reached a value close to zero near the mid section of the substrate. This is seems to be applicable to the in-plane stresses along the Y-axis. See Figure 6 for direction axis and coating-substrate geometry layout. 
The coating and substrate thickness is designated by the symbols $1_{\mathrm{c}}$ and $1_{\mathrm{s}}$ and they represent the incremental thickness of the coating and the substrate respectively, while $\mathrm{L}_{\mathrm{c}}$ and $L_{\mathrm{s}}$ are the total thickness of each entity. The location at the substrate/coating interface is represented by a ratio of zero for $1_{c} / L_{c}$, while a ratio of unity represents maximum coating thickness. Similar convention is used concerning the ratio of the substrate thickness arrangement i.e. $1_{\mathrm{s}} / \mathrm{L}_{\mathrm{s}}$ corresponds to maximum substrate thickness. In figure 7(a) and 7(b) the stresses along the Z-axis and X-Y axes are shown as a function of the normalized distance of the thickness (Z-axis-direction), for both the substrate and the coating. The normalized distance is defined as the ratio of the length increment divided by the total thickness.

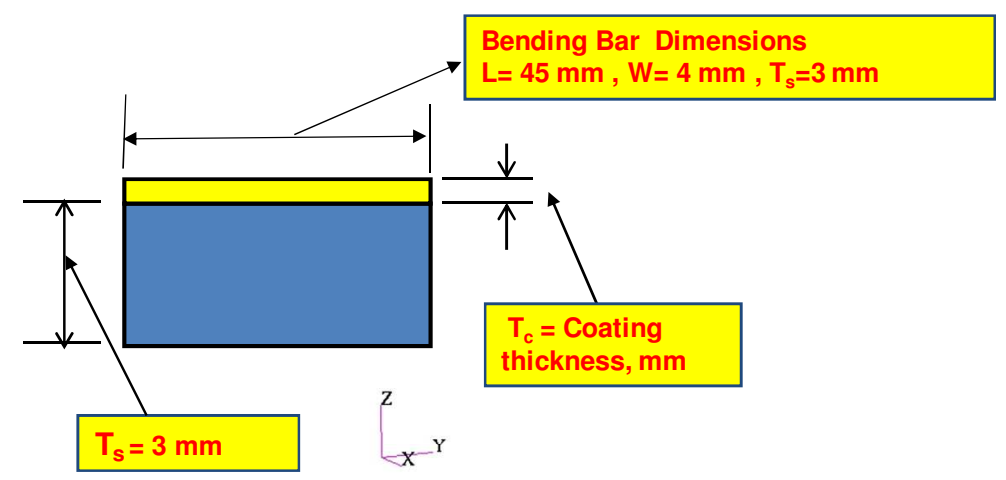

Figure 6. Two dimensional representation of the coating-substrate layout showing through thickness and in-plane directional axis.

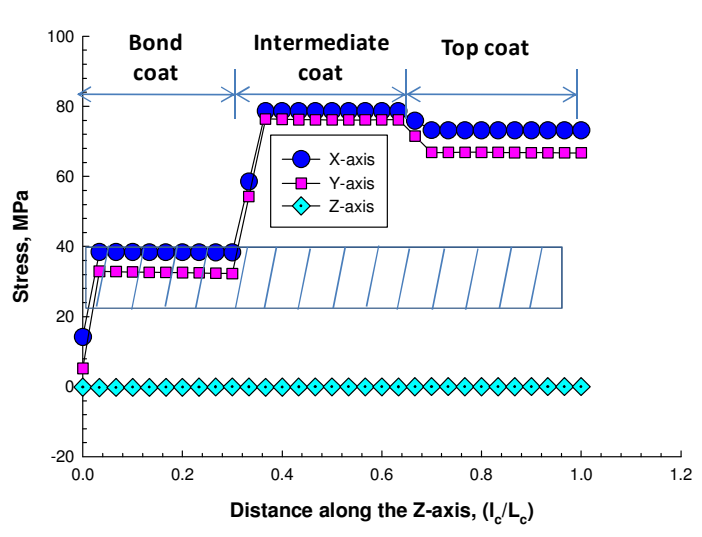

(a) Coating

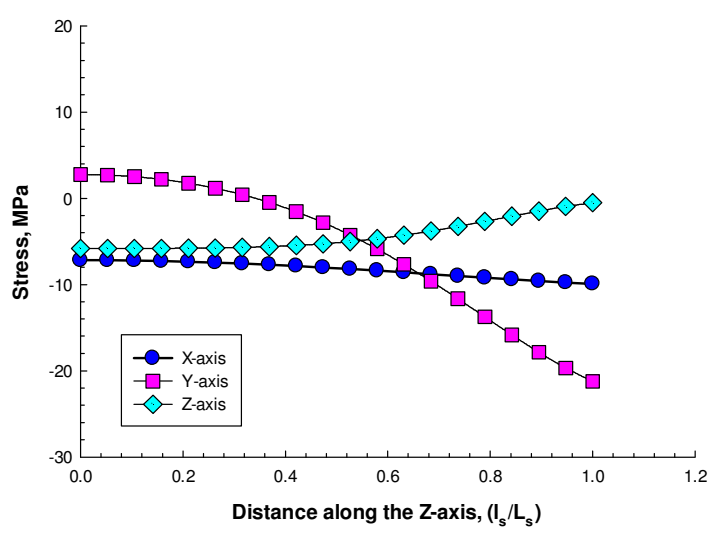

(b) Substrate

Figure 7. Predicted variation in in-plane and through-the-thickness thermal residual stresses with normalized $\mathrm{Z}$ distance for coated $\mathrm{SiC} / \mathrm{SiC}$ composite.

Also noticed is that the predicted stresses in the EBC are much greater than the fracture strength of the coating layers which suggests that the EBC coating on the $\mathrm{SiC} / \mathrm{SiC}$ composite is possibly micro/macro cracked in the as-coated condition. Therefore actual residual stresses in the coating may be much smaller than the predicted stress, and more details concerning these results and analyses can be found in reference [18].

\section{Conclusions}


This study described two combined analytical/experimental options to model the EBC durability. Option one is expressed in a bubble chart illustrating the technical modeling approach and listings of all the corresponding elements that have to be addressed in order to asses and model the durability issues of the EBC. The second option is portrayed in an NDE-FEA modeling approach using imaging data obtained from sources such as computer tomography (CT) and advanced X-ray systems. Reverse engineering principals via the finite element computational method is enlightened and the modeling procedure to analyze tested specimen under thermal and mechanical loading conditions is also described.

Results obtained from the finite element analysis relating to the residual stress effects showed that $\mathrm{z}$-direction (through thickness) stresses are small and negligible, but maximum in-plane stresses can be significant depending on the composition of the EBC constituent layer and the distance from the substrate.

Future work will include recording the baseline microstructure and crystallinity of EBC and thickness variation of individual EBC layers and expose the EBC coated CMC in air and moisture environments at temperatures up to $1400^{\circ} \mathrm{C}$ for up to 500 hours and thermal cycle it without stress in a moisture environment. Crack propagation phenomenon is to be investigated via inducing an artificial crack or an indentation in the EBC and analyses will be conducted under stress and thermal cycling conditions.

\section{References}

[1] D. Brewer, "HSR/EPM Combustion Materials Development Program" Mat. Sci. and Eng., A261, p284-291, (1999).

[2] E.A. Gulbransen and S.A. Jansson, "The High-Temperature Oxidation, Reduction, and Volatilization Reactions of Silicon ad Silicon Carbide," Oxidation of Metals, 4[3] p181-201, (1972)

[3] P.J. Jorgensen, M.E. Wadsworth and I.B. Cutler, "Oxidation of Silicon Carbide," J. Am. Ceram. Soc., 42 (12): p613-616 (1959).

[4] J.L. Smialek, R.C. Robinson, E.J. Opila, D.S. Fox, and N.S. Jacobson, "SiC and $\mathrm{Si}_{3} \mathrm{~N}_{4}$ Recession Due to $\mathrm{SiO}_{2}$ Scale Volatility under Combustor Conditions," $A d v$. Composite Mater, 8 [1], 33-45 (1999).

[5] K. L. More, P. F. Tortorelli, and L. R. Walker, "Effects of High Water Vapor Pressures on the Oxidation of SiC-Based Fiber-Reinforced Composites," Mater. Sci. Forum, 369-372, 385-94 (2001).

[6] K. L. More, P. F. Tortorelli, and L. R. Walker, "High-Temperature Stability of SiCBased Composites in High-Water-Vapor-Pressure Environments," J. Am. Ceram. Soc., 86 [8] 1272-81 (2003)

[7] K.N. Lee, "Current status of environmental barrier coatings for Si-based ceramics," Surface and Coatings Technology, 133-134, 1-7 (2000)

[8] K.N. Lee, D.S. Fox, R.C. Robinson, and N.P Bansal, "Environmental Barrier Coatings for Silicon-Based Ceramics. High Temperature Ceramic Matrix Composites," High Temperature Ceramic Matrix Composites, Edited by W. Krenkel, R. Naslain, H. Schneider, Wiley-Vch, Weinheim, Germany, 224-229 (2001). 
[9] K.N. Lee, D.S. Fox, N.P Bansal, "Rare Earth Environmental Barrier Coatings for $\mathrm{SiC} / \mathrm{SiC}$ Composites and $\mathrm{Si}_{3} \mathrm{~N}_{4}$ Ceramics," J. Eur. Ceram. Soc., 25 [10] 1705-1715 (2005).

[10] D.M. Zhu, N.P. Bansal and R.A. Miller, "Thermal Conductivity and Stability of $\mathrm{HfO} 2-\mathrm{Y} 2 \mathrm{O} 3$ and $\mathrm{La}_{2} \mathrm{Zr}_{2} \mathrm{O}_{7}$ Evaluated for $1650^{\circ} \mathrm{C}$," Advances in Ceramic Matrix Composites IX, N.P. Bansal, J.P. Singh, W.M. Kriven and H. Schnneider (eds.), The American Ceramic Society, Westerville, Ohio, 153, 331-343, (2003).

[11]D.M. Zhu, R.A. Miller and D.S. Fox, “Thermal and Environmental Barrier Coating Development for Advanced Propulsion Engine Systems," NASA TM-2008-215040, January (2008).

[12]D.M. Zhu, and R.A Miller, "Thermal Conductivity and Elastic Modulus Evolution of Thermal Barrier Coatings under High Heat Flux Conditions" J. Therm. Spray Tech., 9, [2], 175-180 (2000).

[13]S. Ramasamy, S.N. Tewari, K.N. Lee, R.T. Bhatt, D. S. Fox, "Mullite-gadolinium silicate environmental barrier coatings for melt infiltrated SiC/SiC composites," Surface \& Coatings Technology 205 (2011) 3578-3581.

[14]MSC/PATRAN Graphics and Finite Element Package. The MacNeal-Schwendler Corporation, 2007, Costa Mesa, CA.

[15]Marc General Purpose Finite Element Analysis Program, the MacNeal-Schwendler Corporation, 2007, Costa Mesa, CA.

[16]) Abaqus Finite Element Code, Abaqus Inc., 534 Forest Avenue, Palo Alto, CA 94301.

[17]ScanIP, Simpleware Ltd, Innovation Centre, University of Exeter, Rennes Drive, EX4 4RN, UK.

[18]Ali Abdul-Aziz and Ramakrishna T. Bhatt, "Modeling Of Thermal Residual Stress In Environmental Barrier Coated Fiber Reinforced Ceramic Matrix Composites"; Journal of Composite Materials, September 21, 2011; 0021998311414950, first published on September 21, 2011 